\title{
Unsteady Mhd free Convective flow in a Rotating System with Dufour and Soret Effect
}

\author{
Dr.S.Anuradha and R.Boopathi \\ *Professor and Head, Department of Mathematics, Hindusthan College of arts and science, Coimbatore- \\ *Research scholar in Department of Mathematics, Hindusthan College of arts and science, Coimbatore -
}

\begin{abstract}
Numerical analysis is used to examine the unsteady MHD free convection and mass transfer fluid flow through a porous medium in a rotating system. Impulsively started plate moving its individual plane is considered. Similarity equations of the corresponding momentum, energy, and concentration equations are derived by introducing a time dependent length scale which infect plays the role of a resemblance parameter. The velocity component is taken to be inversely proportional to this parameter. The effects on the velocity, temperature, concentration, local skin-friction coefficients, Nusselt number, Prandl number, Dufour, Soret number and the Sherwood number of the various important parameters entering into the problem separately are discussed with the help of graphs.
\end{abstract}

Keywords: Numerical analysis, Magnetohydronamics (MHD), Dufour, Soret, Rotating system, Thermal Diffusion, Convective flow and Heat and Mass transfer.

\section{Introduction}

Magnetohydrodynamics (MHD) is the study of the magnetic properties of the electrically conducting fluids. Examples of such magneto fluids include plasmas, liquid metals and salt water or electrolytes. Nowadays the possible use of MHD is to affect a flow stream of an electrically conducting fluid for the purpose of thermal protection, braking, propulsion and control. From the point of applications, model studies on the effect of magnetic field on free, free forced and natural convection flows have been made by several investigators.Alamet al.(2005)studied the Dufour andSoret effects on steady MHD free convective heat and mass transfer flow past a semi-infinite vertical porous plate embedded in a porous medium[1].Alamet al,(2006)studied the Dufour andSoret effects on steady MHD combinedfree-forced convective and mass transfer flow past a semi-infinite vertical plate[2].Alamet al.,(2006)reported the effects of Dufour andSoretlying on unsteady MHD free Convection and mass transfer flow past a vertical porous plate in a porous medium numerically[3].Anjali et al., (2011) givenSoret and Dufour effects on MHD slip flow with thermal radiation over a porous rotating infinite disk[4].Dursunkayaet al.,(1992) studied diffusion-thermo and thermal-diffusion effects in transient and steady natural convection from a vertical surface[5].Emmunuelet al., (2008) have discussed Thermal-diffusion anddiffusion thermo effects on combined heat and masstransfer of a steady MHD convective and slip flow due toa rotating disk with viscous dissipation and ohmicheating[6].Kafoussiaset al.,(1995) studied thermal-diffusion and diffusion-thermo effects on mixed free-forced convective and mass transfer boundary layer flow with temperature dependent viscosity[7].Lavanyaet al., (2004) the effects of heat and mass transfer on two-dimensional steady MHD free convection flow along a vertical porous plate fixed in porous medium in presence of thermal radiation, heat generation, viscous dissipation and chemical reaction under the influence of Dufour andSoret effects[8].Nazmul Islamet al.,(2007) examined the numerical studies are performed to examine the steady MHD free convection andmass transfer fluid flow through a continuously touching porous medium with thermaldiffusion and diffusion thermo past a semi-infinite vertical porous plate in a rotating system[9]. Nazmul Islamet al.,(2008) examined the numerical studies are performed to examine the unsteady MHD free convection andmass transfer fluid flow through a continuously moving porous medium with thermaldiffusion and diffusion thermo past a semi-infinite vertical porous plate in a rotatingsystem[10].Raptiset al., (1985)studied numerically free convection flow through a porous medium bounded by a semi-infinite vertical porous plate[11].Sharma et al.,(2014)analyzed the Influence of chemical reaction,Soret and Dufour effects on heat and mass transfer of a binary fluid mixture in porous medium over a rotating disk[12].

\section{Mathematical Model}

Choose an unsteady MHD free convection and mass transfer flow of an electrically conducting viscous fluid through a porous medium along an infinite vertical porous plate $\mathrm{y}=0$ in a rotating system. The flow is in $\mathrm{x}-$ direction which taken along the plate in the upward direction and y-axis is normal to it. The temperature and the species concentration at the plate are constantly raised from $T_{w}$ and $C_{w}$ to $T_{\infty}$ and $C_{\infty}$ respectively, where $T_{\infty}$ 
and $C_{\infty}$ are the temperature and species concentration of the flow. B is magnetic field acting along the y-axis which is electrically non-conducting.

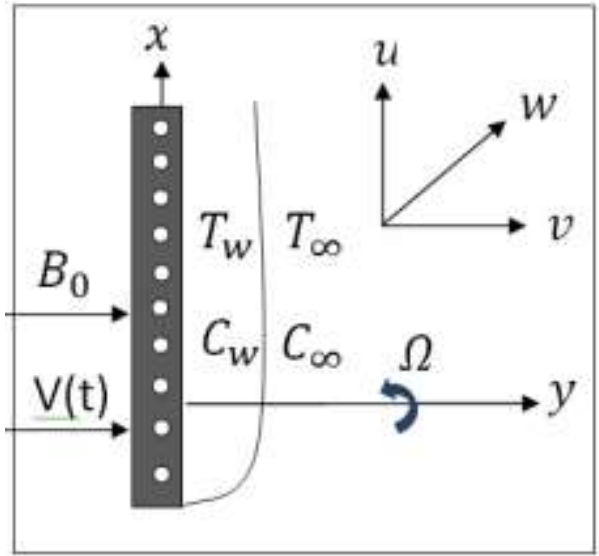

Figure.1. Physical configuration and coordinate system

Under the above assumption the governing boundary layer equations of momentum, energy, and Boussineq's approximations written as follows,

The continuity equation

$\frac{\partial v}{\partial y}=0$

The momentum equations

$\frac{\partial u}{\partial t}+v \frac{\partial u}{\partial y}=g_{0} \beta\left(T-T_{\infty}\right)+g_{0} \beta^{*}\left(C-C_{\infty}\right)+v \frac{\partial^{2} u}{\partial y^{2}}+2 \Omega w-\frac{v}{K^{\prime}} u-\frac{\sigma^{\prime} B_{0}{ }^{2} u}{\rho}$
$\frac{\partial w}{\partial t}+v \frac{\partial w}{\partial y}=v \frac{\partial^{2} w}{\partial y^{2}}-2 \Omega u-\frac{v}{K^{\prime}} w-\frac{\sigma^{\prime} B_{0}{ }^{2} w}{\rho}$

The energy equation

$\frac{\partial T}{\partial t}+v \frac{\partial T}{\partial y}=\frac{k}{\rho c_{p}} \frac{\partial^{2} T}{\partial y^{2}}+\frac{D_{m} k_{T}}{c_{s} c_{p}} \frac{\partial^{2} C}{\partial y^{2}}+q_{r}\left(T-T_{\infty}\right)$

The concentration equation

$\frac{\partial C}{\partial t}+v \frac{\partial C}{\partial y}=D_{m} \frac{\partial^{2} C}{\partial y^{2}}+\frac{D_{m} k_{T}}{T_{m}} \frac{\partial^{2} T}{\partial y^{2}}+K_{r}\left(C-C_{\infty}\right)$

The boundary conditions for the present problem are,

$t \leq 0, u=0, v=0, w=0, T=T_{\infty}, C=C_{\infty}$

for all values of $\mathrm{y}$.

$t>0, u=U_{0}, v=v(t), w=0, T=T_{w}, C=C_{w}, a t$ at $y=0$

$t>0, u=0, v=0, w=0, T \rightarrow T_{\infty}, C \rightarrow C_{\infty}$, at at $y \rightarrow \infty$

To obtain similar solution we introduce a similar parameter $\sigma$, is the time dependent length scale,

$\sigma=\sigma(t)$

we take $v=-v_{\mathrm{o}} \frac{\nu}{\sigma}$ the equation (1) is satisfied and we assume that,

$\sigma=\sqrt{2 c v t}, \sigma=0$ when $t=0, \sigma=2 \sqrt{v t}$

We now introduce the following dimensionless variables to attain a similarity solution

$\eta=\frac{y}{\sigma}, f(\eta)=\frac{u}{U_{0}}, g(\eta)=\frac{w}{U_{0}}, \theta(\eta)=\frac{T-T_{\infty}}{T_{w}-T_{\infty}}, \phi(\eta)=\frac{C-C_{\infty}}{C_{w}-C_{\infty}}$

Where we use the following physical quantities,

$G_{r}=\frac{g_{0} \beta\left(T_{w}-T_{\infty}\right) \sigma^{2}}{U_{0} v}, G_{m}=\frac{g_{0} \beta^{*}\left(C_{w}-C_{\infty}\right) \sigma^{2}}{U_{0} \nu}, M=\frac{\sigma^{\prime} B_{0}{ }^{2} \sigma^{2}}{\rho v}, R=\frac{\Omega \sigma^{2}}{v}$, 


$$
P_{r}=\frac{\rho v c_{p}}{k}, D_{f}=\frac{D_{m} k_{T}}{c_{s} c_{p} v} \frac{\left(C_{w}-C_{\infty}\right)}{\left(T_{w}-T_{\infty}\right)}, S_{c}=\frac{v}{D_{m}}, S_{r}=\frac{D_{m} k_{T}}{v T_{m}} \frac{\left(T_{w}-T_{\infty}\right)}{\left(C_{w}-C_{\infty}\right)}
$$

In view of the above quantities, the continuity Equation (1) is identically satisfied while Equations (2)-(5) become

$$
\begin{aligned}
& f^{\prime \prime}+2 \xi f^{\prime}+G_{r} \theta+G_{m} \phi-K f-M f+2 R g=0 \\
& g^{\prime \prime}+2 \xi g^{\prime}-K g-M g-2 R f=0 \\
& \theta^{\prime \prime}(\eta)+2 \xi P_{r} \theta^{\prime}(\eta)+P_{r} D_{f} \phi^{\prime \prime}(\eta)+P_{r} Q_{r} \theta(\eta)=0 \\
& \phi^{\prime \prime}(\eta)+2 \xi S_{c} \phi^{\prime}(\eta)+S_{c} S_{r} \theta^{\prime \prime}(\eta)+S_{c} K_{r} \phi(\eta)=0
\end{aligned}
$$

Where, $\xi=\eta+\frac{v_{0}}{2}$.

The corresponding boundary conditions are,

$$
\begin{aligned}
& f=1, g=0, \theta=1, \phi=1, \text { at } \eta=0 \\
& f=0, g=0, \theta=0, \phi=0, \text { as } \eta \rightarrow \infty .
\end{aligned}
$$

In all the above equations primes denote the differentiation with respect to $\eta$. Where $Q_{r}$ anin figure $\mathrm{d} K_{r}$ be heat source parameter and chemical reaction parameter respectively.

\section{Numerical Analysis}

In this study we analyze unsteady MHD free convective and mass transfer flowthrough a porous medium with thermal diffusion, dufour and soret effect past an infinite vertical porous plate in a rotating system. The governing boundary layer equations are transformed to ordinary differential equations by using similarity transformation. Then they are solved by superposition method with using Runge-KuttaMerson Integration Scheme. The obtained numerical results are illustrated graphically for different values done by using Mathematica computer language. From the process of numerical computation the fluid velocity, temperature, concentration, energy, prantdl, Nusseltnumbers are analyzed.

\section{Results and Discussion}

From this research we have found various changes in many parameters by increasing the values of Prandtl number and Dufour number. The results are displayed graphically for different parameters $\left(\mathrm{V}, \mathrm{T}, \mathrm{C}, \mathrm{S}_{\mathrm{h}}\right.$, $\mathrm{N}_{\mathrm{u}}$ ) In figure 2 when thePrandtl number increases the velocity profile decreases. Also from figure 3 the increasing of Prandtl number decreases the temperature profile. In figure 4 the Prandtl number increases and the concentration profile increases. In figure 5, 6 and 7 the Prandtl increases the skin friction and decreases the Nusselt number but decreases the Sherwood number. From figure 8 and 9as the Dufour number increases then the velocity and temperature profiles decreases. In figure 10Dufour number increases and the concentration profile decreases. In figure 11, 12 and 13 the Dufour number increases the skin friction, increases the Nusselt number but decreases the Sherwood number.

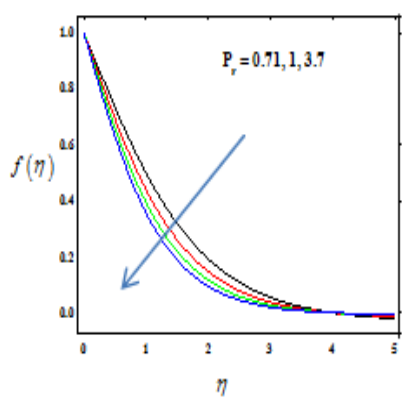

Figure.2. Velocity profile for different values of $P_{x}$ with $\mathrm{V}_{0}=0.5, \mathrm{G}_{\mathrm{r}}=10.0, \mathrm{G}_{\mathrm{m}}=4.0, \mathrm{M}=0.5$, $R=0.2, S_{s}=1.0, S_{c}=0.6, D=0.2, K=0.5$.

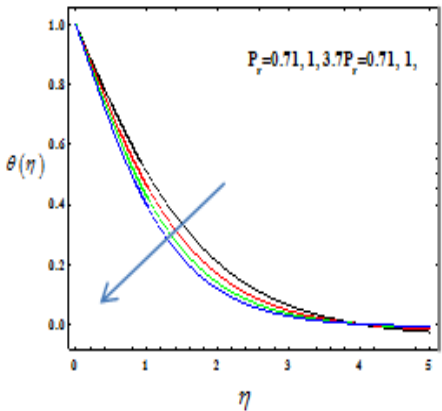

Figure.3. Temperature profile for different values of $P_{r}$ with $\mathrm{V}_{0}=0.5, \mathrm{G}_{\tau}=10.0, \mathrm{G}_{\mathrm{m}}=4.0, \mathrm{M}=0.5$, $\mathrm{R}=0.2, \mathrm{~S}=1.0, \mathrm{~S}_{\mathrm{a}}=0.6, \mathrm{D}=0.2, \mathrm{~K}=0.5$.

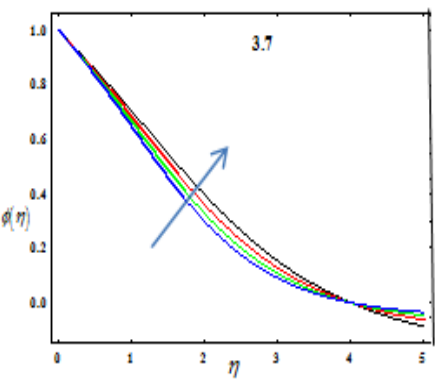

Figure.A. Concentration profile for different values of $P$ with $V_{0}=0.5, G_{r}=10.0, G_{m}=4.0, M=0.5$, $\mathrm{R}=0.2, \mathrm{~S}_{\mathrm{r}}=1.0, \mathrm{~S}_{\mathrm{c}}=0.6, \mathrm{D}_{\mathrm{s}}=0.2, \mathrm{~K}=0.5$. 


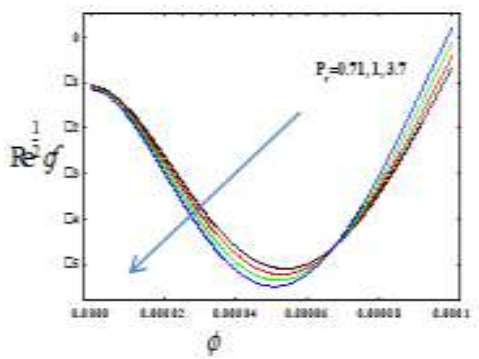

Figere.5. Slin Frictica protile for diflerent ralies of $\mathrm{F}$ mis $\mathrm{V}_{\mathrm{a}}=0 \mathrm{~s}, \mathrm{G},=10 \mathrm{I}, \mathrm{G}_{\mathrm{z}}=40, \mathrm{MI}=0.5, \mathrm{R}=1$. $5=10,5,0=0,0,0=1, \mathrm{~K}=0.5$.

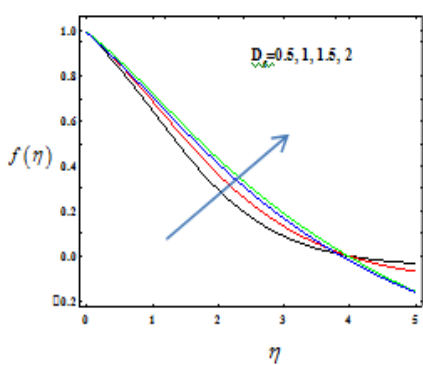

Figures. Velocity profile for different values of $D$ with $\mathrm{V}_{\mathrm{o}}=0.5, \mathrm{G}=10.0, \mathrm{G}_{\mathrm{m}}=4.0, \mathrm{M}=0.5$, $\mathrm{R}=0.2, \mathrm{~S}_{\mathrm{r}}=1.0, \mathrm{~S}_{\mathrm{c}}=0.6, \mathrm{D}=0.2, \mathrm{~K}=0.5$
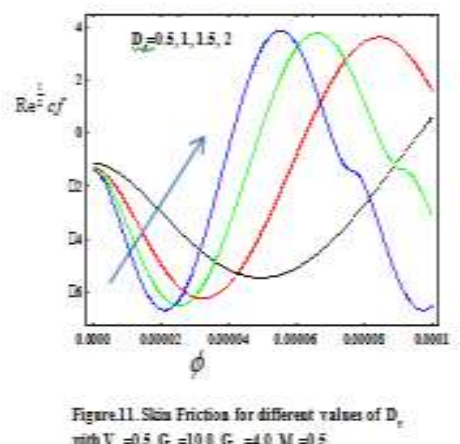
Titit $\mathrm{V}_{2}=05, \mathrm{G}=10 \mathrm{~s}, \mathrm{G}=40, \mathrm{M}=0 \mathrm{5}$,

$\mathrm{R}=02, \mathrm{~S},=10, \mathrm{~S}=1.6, \mathrm{D} \Rightarrow 12, \mathrm{~K}=0.5$

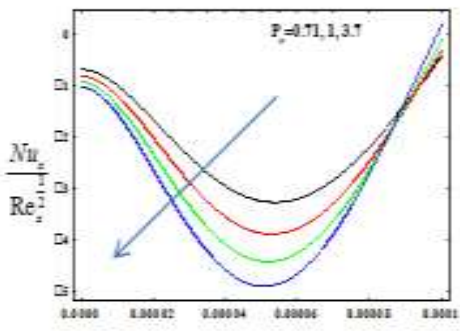

(6)

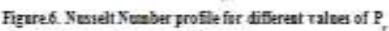
$\operatorname{rith} V=0,5, G=100, G=19, Y=05$,

$\mathrm{B}=12,5=10,5,0.6, \mathrm{D},=02, \mathrm{X}=15$

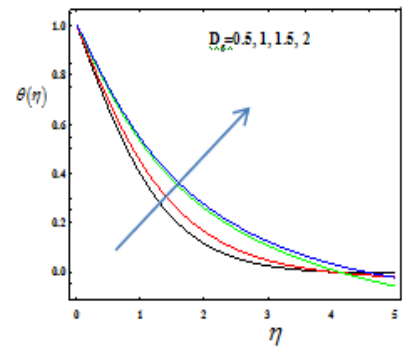

Figure. Temperature profile for different values of $D$ with $\mathrm{V}_{0}=0.5, \mathrm{G}_{\mathrm{r}}=10.0, \mathrm{G}_{\mathrm{m}}=4.0, \mathrm{M}=0.5$,

$R=0.2, S=1.0, S=0.6, D=02, K=0.5$

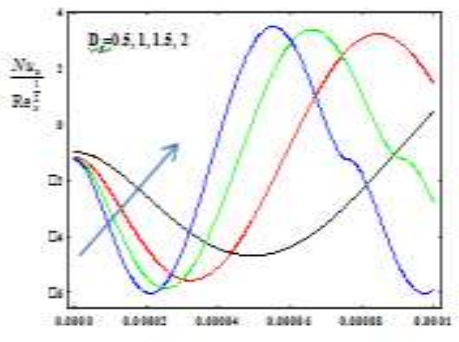

$\phi$

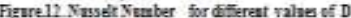
nift $\mathrm{V}, 0=5, \mathrm{G}=10 \mathrm{~s}, \mathrm{G}=40, \mathrm{Il}=0 \mathrm{5}$

$\mathrm{R}=02, \mathrm{~S}=1 \mathrm{~L}, \mathrm{~S}, \mathrm{~s}, \mathrm{D}, \mathrm{D}=12, \mathrm{~K}=0 \mathrm{~S}$

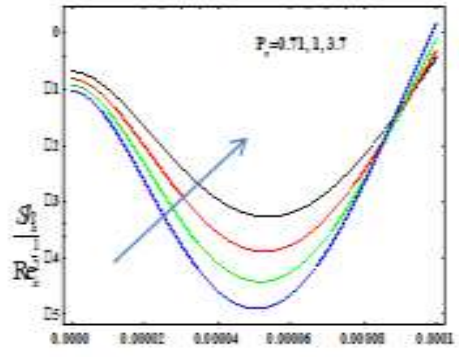

$\phi$

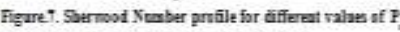
vint $T_{0}=15, G_{0}=100, G_{n}=10,1,=15, R=0.2$

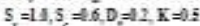

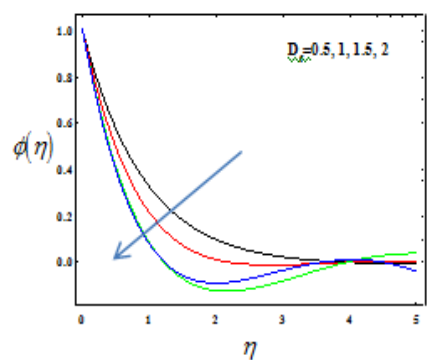

Figure.10. Concentration profile for different values of $D$ with $\mathrm{V}_{0}=0 . \overline{,}, \mathrm{G}_{\mathrm{x}}=10.0, \mathrm{G}=4.0, \mathrm{M}=0 . \overline{5}$, $\mathrm{R}=02, \mathrm{~S}=1,0, \mathrm{~S}=0.6, \mathrm{D}=02, \mathrm{~K}=0.5$.

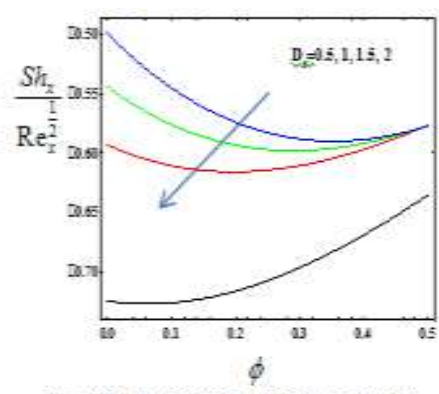

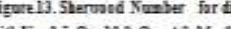
rith $V=15, G=100, G=10, M=15$, $\mathrm{R}=1,5,1.0,5 \Rightarrow 0, \mathrm{D}, 0.1, \mathrm{x}=1.5$.

\section{Conclusion}

This study is an investigation of flow, heat and mass transfer behavior of magneto hydrodynamic flow towards a rotating system through a porous medium with Dufour and Soret effects. The results obtained from this study are given below,

- Velocity boundary layer thickness increases with increase in Dufour Number.

- Mass Transfer is enhanced by the increase in Dufour Number.

- Increasing of Prandtl Number there is a decrease in velocity profile.

- The Dufour Number increases then the velocity and temperature profiles decreases.

\section{References}

[1]. Alam.M.,S and M.M.,Rahman(2005), "Dufour and soret effect on MHD Free Convective Heat and Mass Transfer Flow past a Vertical Flate Plate Embedded in a Porous Medium",J. Naval Architecture and Marine Engng, 2(1), pp.55-65.

[2]. Alam.M.,S(2006), "Dofour and Soret Effects on Steady MHD Combined Free-Forced Convective and Mass Transfer Flow Past a Semi-infinite Vertical Plate",Thammasat Int. J. Sci. Technol., 11, pp. 1-12.

[3]. Alam.M.,S, Rahman.M.,MandSamad.M.,A(2006), "Dufour and Soret effects on Unsteady MHD Free Convection and Mass Transfer Flow Past a Vertical Porous Plate in a Porous Medium",Non-linear Analysis Modelling and Control, 11, pp.217-226.

[4]. $\quad$ Anjali Devi.S.,P and Uma Devi.,R, (2011), "Soret and Dufour Effects on MHD Slip Flow with Thermal Radiation over a porous Rotating Infinite disk",Communication in Nonlinear Science and Numerical Stimulation, 16(4), pp.1917-1930.

[5]. Dursunkaya.,Z and Worek.W.,M(1992), "Diffusion-Thermo and Thermal-Diffusion Effects in Transient and Steady natural Convection from Vertical Surface",Int. J. Heat Mass Trans., 35(8), pp.2060-2065. 
[6]. Emmunuel.,O,Jonathan.S, Robert.,H(2008), “Thermal-Diffusion and Diffusion-Thermo Effects on Combined Heat and Mass Transfer of a Steady MHD Convective and Slip Flow due to a Rotating Disk with Viscous Dissipation and ohmic hating”, Int. Commun. Heat Mass Transfer, 35, pp.908-915.

[7]. Kafoussias.N.,G, Williams.E.,M(1995), "Thermal-Diffusion and Diffusion-Thermo Effects on Mixed Free-Forced Convective and Mass Transfer Boundary Layer Flow with Temperature Dependent Viscosity",Int.J. Engng. Sci., 33, pp.1369-1384.

[8]. Lavanya.,B and LeelaRatnam (2004), "Dufour and Soret effects on Steady MHD Free Convective Flow Past a Vertical Plate Embedded in a Porous Medium with Chemical Reaction, Radiation Heat generation and Viscous Dissipation", Advances in Applied Science Research, 5, pp.127-142.

[9]. Nazmul Islam and Md.MahmudAlam (2007), "Dufour and Soret Effects on Steady MHD Free Convection and Mass Transfer Fluid Flow Through a Porous Medium in a Rotating System", Journal of Naval Architecture and Marine engineering, 4, pp.43 55.

[10]. Nazmul Islam and Md.MahmudAlam (2008), "Dufour and Soret Effects on Steady MHD Free Convection and Mass Transfer Fluid Flow Through a Porous Medium in a Rotating System",Bangladesh J. Sci. Ind. Res. 43(2), pp.159-172.

[11]. Raptis.,A and Perdikis.P.,C (1985), "Unsteady Flow Through a Porous Medium in the Presence of Free Convection", Int.Comm.Heat Mass Trans., 12, pp.697-704.

[12]. Sharma B.,R and Borgohain.,D (2014), "Influence of Chemical Reaction, Soret and Dufour Effects on Heat and Mass Transfer of a Binary Fluid Mixture in Porous Medium over a Rotating Disk", IOSR Journal of Mathematics, 10(6), pp. 73-78. 